\title{
POLÍTICAS DE MEMORIA EN ESPAÑA
}

\author{
MEMORY POLICIES IN SPAIN
}

\author{
Juan Luis Porcar Orihuela \\ Universidad Jaume I. Castellón. España/Spain \\ juanluis@memoriacastello.cat
}

Recibido/Received: 22/07/2015

Modificado/Modified: 25/09/2015

Aceptado/Accepted: 04/10/2015

\section{RESUMEN}

La construcción del pasado de una comunidad y su rememoración, es decir la aceptación por la sociedad de una memoria histórica y colectiva que sea compartida, está produciendo numerosos estudios y un interesante debate historiográfico en Europa. En España, estas investigaciones y debate historiográfico vienen acompañadas de las reivindicaciones del movimiento de la memoria histórica que, en representación de una importante parte de la sociedad, exige políticas de reparación para las víctimas de la guerra y del franquismo y políticas públicas de memoria por parte del Estado y sus instituciones. El desarrollo de estas políticas por parte del Estado contrasta con las políticas impulsadas en otros países de nuestro entorno y de América Latina, y con las desarrolladas en algunas comunidades autónomas.

\section{PALABRAS CLAVE}

Represión, Derechos Humanos, víctimas, franquismo, memoria.

\section{SUMARIO}

1. Introducción. La memoria en nuestro tiempo. 2. Derecho a la memoria y políticas de memoria. 3. Políticas de memoria en España. Bibliografía.

\begin{abstract}
The construction of the past of a community and its remembrance, i.e., the acceptance by the society of a historic and collective memory that is shared, is producing numerous studies and an interesting historiographical debate in Europe. In Spain, these investigations and historiographical debate come accompanied by the demands of the movement of historical memory that requires repair policies for victims of war and of the Franco regime and policy public memory by the State and its institutions on behalf of an important part of society. The development of these policies by the State contrasts with policies driven in other countries around us and Latin America, and with those developed in some autonomous communities.
\end{abstract}

\section{KEYWORDS}

Repression, Human Rights, victims, Francoism, memory.

\section{CONTENTS}

1. Introduction. The memory in our time. 2. Right to the memory and memory policies. 3. Policies of memory in Spain. References. 


\section{INTRODUCCIÓN. LA MEMORIA EN NUESTRO TIEMPO}

Los estudios, debates y publicaciones referentes a la memoria histórica han experimentado un auge sin precedentes a finales del siglo XX y principios del actual, siendo una constante no solamente en el ámbito académico, también en los medios de comunicación, penetrando en la esfera política y el tejido social.

La sociedad actual muestra una sensibilización en todo lo relacionado con su memoria, es decir, con la construcción de un pasado y su rememoración dentro de un marco de referencia colectivo en el presente. La memoria histórica se refiere a episodios del pasado que generalmente el sujeto no ha experimentado personalmente y los mantiene vivos por medio de conmemoraciones, reforzando así los lazos de identidad de una comunidad. A la historia como saber científico y acumulativo de los hechos pasados se opondría, pues, la memoria, entendida como la representación del pasado cultivada por los contemporáneos y sus descendientes; como la "construcción social del recuerdo" que para Gaborit (2006) busca desde el dolor la reconstrucción del tejido social, un recuerdo compartido que se convierte en elemento central para la continuidad simbólica de las identidades colectivas (Rodrigo, 2006:149).

La memoria colectiva es el recuerdo de esos acontecimientos en función de nuestro contexto social, al recordar desde el punto de vista del grupo o grupos que comparten una identidad común, y se transmite aunque el individuo deje de existir; adquiere una dimensión social estableciendo unos puntos de referencia para un marco colectivo y una homogenización de las representaciones del pasado reduciendo la diversidad de los recuerdos, es una forma de organizar una sociedad armada de unos referentes ideológicos para argumentar su presente (Rodrigo, 2006).

La intensidad de los debates y prácticas al respecto responde claramente a coyunturas políticas concretas. Así ha ocurrido en diferentes países, que han impulsado políticas de memoria más o menos enérgicas de signo democrático, para tratar de restañar las heridas abiertas por un pasado reciente traumático marcado, según los casos, por el apartheid, la guerra, los genocidios, las dictaduras o el totalitarismo. En el caso de España las investigaciones y el conocimiento de nuestro pasado más reciente y traumático han conducido al debate social y político sobre la memoria, a las demandas de justicia y reparación por parte de familiares de represaliados y movimientos memorialísticos, a la aprobación de la llamada Ley de la Memoria Histórica y de otras iniciativas autonómicas. Se trata en su conjunto de políticas de memoria vinculadas a procesos de democratización todavía en marcha o que intentan consolidarse y a la lucha por los derechos humanos o por expandir y fortalecer las esferas públicas de la sociedad civil.

\section{DERECHO A LA MEMORIA Y POLÍTICAS DE MEMORIA}

\subsection{Políticas y principios de memoria}

El derecho a la memoria se presenta como una obligación ética y política de la sociedad que comparte una tragedia colectiva con unas memorias y una historia que adolecen de un reconocimiento insuficiente (Gálvez, 2008:103). Es interesante en este sentido el debate historiográfico abierto sobre la constatación de la existencia de una pluralidad de memorias relegadas en el ámbito de la historia, sobre la crítica del discurso histórico dominante y la aparición de los Derechos Humanos como base jurídica y ética para la reconstrucción de nuestro pasado traumático. El derecho a la memoria y su recuperación representan un papel 
preventivo desde el punto de vista social, desmantelando los mecanismos que posibilitaron la barbarie, deslegitiman los argumentos que hasta ahora han justificado la impunidad. Fijan las bases de la concordia, la reconciliación y la paz para una comunidad.

Según Carmen Molinero las instituciones democráticas deben impulsar la incorporación del conocimiento riguroso del pasado a la memoria colectiva y las políticas institucionales de memoria dicen mucho de los valores éticos y cívicos subyacentes en un sistema político, la memoria pública no es espontánea sino resultado de una selección de hechos para el recuerdo. En este sentido es importante destacar el impacto que la vía política puede tener para la transformación del pasado, las instituciones democráticas deben ser conscientes del resultado terapéutico para la sociedad; el poder de los represores en las transiciones marcan la capacidad de las democracias para afronta su pasado. Las políticas públicas de memoria se impulsarán por medio de los organismos del Estado y de la sociedad civil, esta se beneficiará con la incorporación de las víctimas a una sociedad genuinamente reconciliada (Méndez, 2013).

\subsection{Justicia transicional}

Hay tres daños referidos a las víctimas del terror y la violencia política: uno personal (la muerte, el secuestro, la tortura, la amenaza, etc.), uno político (el asesinado es negado en su derecho a la ciudadanía) y uno social (la sociedad atravesada por la violencia queda fracturada y empobrecida). Hablar de la justicia referida a la violencia política contemporánea significa enfrentar ese triple daño. Hacer justicia con las víctimas del crimen significa reconocer una deuda no reparable respecto a ellas. En el ámbito político y social significa ubicar en el centro del nuevo proyecto político el pleno reconocimiento de la ciudadanía de las víctimas y recuperar para la sociedad a las víctimas y los victimarios (Mate, 2009).

Garantizar los derechos de las víctimas de las violaciones de los derechos humanos es un medio para construir la paz y consolidar la democracia en una sociedad que ha vivido una experiencia traumática. Solamente si se garantizan estos derechos de las víctimas la paz será real y justa. La Justicia Transicional es la serie de procesos y mecanismos asociados (judiciales y extrajudiciales) con los intentos de una sociedad por resolver problemas de un pasado de abusos a gran escala a fin de que los responsables rindan cuentas, de que se sirva a la justicia y se logre la reconciliación (Chinchón, 2010). En situaciones de procesos de tránsito de guerras, regímenes autoritarios hacia la paz y la democracia, la justicia transicional busca procesos de reconciliación justos y duraderos porque la construcción de la democracia o la reconstrucción de una comunidad, después de un conflicto armado o de una situación de violación de los derechos humanos, debe solucionar el conflicto subyacente para evitar que vuelva a producirse en el futuro. La reconciliación es un proceso mediante el cual una sociedad evoluciona de un pasado dividido a un futuro compartido; no puede ser una alternativa a la verdad y la justicia, ni una excusa para la impunidad, para el olvido o para un simple perdón, éste es un acto privado entre el agresor y la víctima, y no puede haber perdones colectivos sin tener en cuenta a las víctimas. El Estado no es quién para subrogarse la facultad de perdonar y las amnistías no pueden ser "perdones" sino suspensiones de determinadas consecuencias legales del delito.

La Justicia Transicional tiene como objetivo la lucha contra la impunidad, y promocionar la obligación de los Estados de proteger a las víctimas de violaciones de los derechos humanos preservando que dispongan de los mecanismos necesarios para garantizar el derecho a un recurso efectivo ante la administración de justicia, el Estado tiene el deber de 
respetar y hacer respetar los Derechos Humanos según el Derecho Internacional, adoptando las medidas oportunas y eficaces para luchar contra la impunidad, pues esta comporta la violación del derecho a la verdad, a la justicia y a la reparación.

\subsubsection{El derecho a la verdad. Los archivos de la represión}

El derecho a la verdad se configura como un derecho individual pero también como un derecho de cada pueblo a conocer la verdad sobre su pasado. En consecuencia, los Estados tienen la obligación de preservar archivos y pruebas que salven del olvido la memoria colectiva. El reconocimiento de este derecho tiene también como objetivo evitar que surjan tesis revisionistas y negacionistas, asegurar el derecho de las víctimas y de sus familias a conocer las circunstancias en que se cometieron las violaciones de derechos humanos de qué fueron objeto y, así mismo, la obligación del Estado de hacer efectivo este derecho con procesos no judiciales que complementen la función del poder judicial, como por ejemplo con el establecimiento de comisiones de la verdad.

La verdad reconocida socialmente deriva en un reconocimiento de las víctimas cuando la sociedad en su conjunto da su validez a esa verdad -con una declaración oficial o judicial, o una disculpa pública- por ejemplo. El derecho a la verdad reconocido por el Tribunal Europeo de Derechos Humanos y la Corte Interamericana de Derechos Humanos supone la verificación de los hechos, su revelación pública, la disculpa, el reconocimiento y la celebración de homenajes y conmemoraciones, la decisión judicial del restablecimiento de la dignidad y reputación de las víctimas.

En el derecho a la verdad es importante la preservación de los archivos, pues son testigos de las violaciones de los Derechos Humanos. Las víctimas tienen derecho a conocer la verdad, que se haga justicia y que se reparen los daños causados. El derecho a la verdad está directamente relacionado con el análisis y la investigación histórica, apoyando al papel de los historiadores y convirtiéndose en elementos esenciales en un proceso de justicia transaccional y de reconciliación, mediante una verdad reconocida oficial y públicamente. La llamada -por algunos autores como Josefina Cuesta-, cultura del recuerdo, se extiende a varios ámbitos de acción como el de la investigación científica de la verdad que tiene que impulsar los conocimientos históricos y posibilitar los otros ámbitos: el de la expresión mediante la estética del pasado del que se ha perdido, y sobre todo, el que trata de las víctimas y los verdugos desde una perspectiva jurídica y biográfica (Cuesta, 1998). Los historiadores tienen que estudiar los documentos para conocer y relatar los hechos sobre los cuales, se podrán articular políticas de memoria que contemplan la acción de la justicia y la reparación de las víctimas. Es necesario que todos los archivos documentales estén preservados y que al mismo tiempo se facilite la consulta, de este modo se favorecen los trabajos de investigación, tal como lo destacan diferentes resoluciones de organismos internacionales.

Los procesos judiciales no son el único mecanismo para garantizar el derecho a la verdad por parte de los estados, encontramos también procedimientos administrativos y civiles, las investigaciones de entidades de Derechos Humanos, los proyectos históricos y los limitados a la investigación y documentación de los hechos: las comisiones de la verdad. Las comisiones de la verdad son organismos oficiales que investigan la violación de los derechos humanos en un periodo histórico concreto, son temporales, no son judiciales, intentan esclarecer los hechos creando un registro histórico de los abusos cometidos, los informes elaborados por estas comisiones de la verdad ayudan a esclarecer la veracidad de los hechos, promueven la responsabilidad de los autores de violaciones de derechos humanos, son una plataforma pública para que las víctimas puedan sentirse reparadas, protagonizan el debate público, 
complementan la acción de la justicia y recomiendan reparaciones para las víctimas a la vez que reformas institucionales y legales necesarias; producen además un efecto disuasorio de los hechos y permiten a las sociedades extraer lecciones válidas para la construcción del futuro siendo un referente histórico para la memoria colectiva en la cual inserta el sufrimiento y la reparación de las víctimas (Schabas, 2006); y pueden dar lugar a un castigo social efectivo, sobre todo cuando la aplicación de la justicia es difícil porque ha pasado mucho tiempo, los asesinos ya no viven o se han aplicado leyes de amnistía (Armengou, 2004). Una comisión de la verdad necesita voluntad política y consenso social y político para llevarse a cabo, ofreciendo la práctica internacional precedentes válidos para España (Pérez González, 2013). Los países sometidos a dictaduras que no recuperan su memoria histórica con comisiones de la verdad como España y Alemania, trasladan el problema a las generaciones siguientes, el poder que mantienen los represores durante las transiciones marca la capacidad de las democracias para afrontar el pasado, situación que se repite en países tan diferentes como Chile, Argentina, Guatemala o Sudáfrica.

\subsubsection{El derecho a la justicia}

Los estados deben crear un entramado judicial para la denuncia, investigación y enjuiciamiento de casos de violaciones de los derechos humanos; solo por estado de necesidad, de supervivencia de la nación o de amenaza seria de golpe de estado se podría entender el no cumplimiento de su obligación general de castigar y procesar a los culpables. El derecho a la justicia implica importantes obligaciones del Estado en materia de administración de justicia para evitar abusos o irregularidades en la aplicación de los mecanismos judiciales encomendados al enjuiciamiento de violaciones de derechos humanos y de crímenes internacionales, como por ejemplo la declaración de prescripción y la adopción de amnistías -leyes éstas que son contrarias al derecho internacional por ser violaciones del derecho a la justicia internacionalmente reconocido- para este tipo de crímenes o la concesión de asilo, la invocación de la obediencia debida, la actuación como cargo oficial o la competencia de tribunales militares para el conocimiento de violaciones de derechos o crímenes internacionales.

\subsubsection{La reparación de las víctimas}

El derecho y la jurisprudencia referidos a los derechos humanos reconocen a las víctimas de violaciones de estos derechos, el derecho a la reparación, en el marco del cual se contemplan el desarrollo de políticas de memoria (Gómez Isa, 2006:23-24). Sin reparación por las violaciones de los derechos humanos y sin tener en cuenta la memoria de las víctimas, los intentos de preservar la paz se pueden enfrentar a obstáculos insalvables (Gómez Isa, 2007).

El derecho a la reparación comporta obligaciones para el Estado en beneficio de las víctimas de violaciones de derechos humanos. Hay numerosas medidas extraídas de la práctica internacional: reformas institucionales, medidas de justicia transicional de carácter administrativo como la separación de funcionarios y agentes implicados en las violaciones de los derechos humanos, el desmantelamiento de las fuerzas armadas paramilitares, o reformas legislativas para eliminar leyes o mecanismos que contribuyan a la impunidad -como leyes discriminatorias o que permitan tribunales de emergencia-, medidas de reparación económica o relativas a la eliminación de la simbología que exalte a represores y culpables de las violaciones de los derechos humanos. Se han adoptado diferentes medidas de reparación según países: en forma de indemnizaciones como en Alemania, con la restitución de 
propiedades confiscadas, la creación de planes de pensiones para las víctimas de las violaciones de derechos humanos durante una dictadura entre otras medidas de índole económica en Chile, satisfacciones públicas y morales (condena de los abusos de derechos humanos, garantías de no repetición, homenajes, reparaciones no materiales en materia de educación, vivienda o salud), puesta en práctica de reformas legislativas en materia de derechos humanos, como por ejemplo la tipificación de la "desaparición forzada" en Argentina.

Las reparaciones son un proceso y no un momento concreto en el que se llevan a cabo determinados actos simbólicos y se entregan a las víctimas algunos beneficios económicos y otro tipo de ayudas. Estas medidas simbólicas de reparación son tan importantes tanto para las víctimas individuales como para el conjunto de la sociedad, significando todo un conjunto de medidas que tienden a modificar el imaginario político y social en el que se tienen que insertar las víctimas. En el fondo, nos encontramos ante un proceso político que busca la reconstitución de la comunidad política, un nuevo equilibrio en la sociedad en el que las víctimas sean reconocidas en su condición de víctimas y pasen a ocupar un nuevo papel en el espacio político y social (Gómez Isa, 2007). Las conmemoraciones ayudan a rememorar eventos colectivos: revisten de dignidad, mediante rituales, los sentimientos de los sobrevivientes. En situaciones de violencia organizada las víctimas y familiares no han podido pronunciar en público sus nombres, hablar de las circunstancias de la muerte o desaparición y señalar a los culpables. Las víctimas deben estar presentes en todo proceso de reparaciones, son quienes han experimentado el sufrimiento y quienes mejor conocen sus necesidades y prioridades en materia de reparación, ese sentimiento de participación y de reconocimiento público es esencial e influye positivamente en su autoestima. En los últimos años las víctimas y sus asociaciones han ganado terreno en el ámbito político y social y el ejercicio de su presión y demandas ha sido clave para la aprobación de adecuados programas de reparación, pero hay factores que limitan su capacidad de influir en procesos de reparaciones, su competencia y su politización. La reparación no puede convertirse en un mero sustituto de la verdad y la justicia, como en ocasiones se pretende, ya que ello equivaldría a querer comprar el silencio y la injusticia. La reparación no tiene una dimensión meramente económica, sino que se tiene que abordar como un intento de reparar el daño causado a las víctimas y de buscar un nuevo equilibrio político y social.

\section{POLÍTICAS DE MEMORIA EN ESPAÑA}

El reconocimiento y recuperación de la memoria de las víctimas de la represión en España es una asignatura pendiente del sistema democrático actual. Al espacio público, la memoria democrática antifascista y antifranquista, como portadora de valores éticos y como motor de los cambios del siglo XX, no ha tenido reconocimiento como patrimonio común; más bien al contrario, ha abierto conflictos en nuestra historiografía, en la política y la sociedad. Esta toma de conciencia de la recuperación de la memoria histórica, aparece a finales del siglo pasado por la necesidad de romper el silencio y el olvido en que se encuentran inmersas las víctimas del franquismo. Colectivos y grupos de investigación histórica actúan como interlocutores de personas que han sentido la necesidad de relatar su experiencia, su memoria escondida. 


\subsection{El caso español. La Transición}

El final del franquismo transmitió que el desarrollo económico ofreció años de paz y estabilidad frente al desorden y caos que suponía la Republica. En la transición temas como el terrorismo, las tensiones sociales, el miedo a una posible intervención del ejército provocó que gran parte de la sociedad valorará más la paz que otras metas como la democracia, la libertad y la justicia; predominando una desconfianza ante el desorden y el miedo a la guerra que dio lugar a la naturaleza pactada de la transición española. Josefina Cuesta rechaza la idea de una transición amnésica y se decanta por la de una transición memoriosa, silenciosa en algunos campos, como el político o el de la justicia -amnistía no es amnesia-, pero alimentada por el recuerdo colectivo -social y político- de los traumas pasados, y por los recuerdos personales de un pasado reprimido, excluido y por el de víctimas desaparecidas. Flores en las cunetas de carreteras o de caminos, o la propia literatura y la filmografía constituían un grito permanente de esa memoria (Cuesta, 2007). Santos Juliá considera que no ha habido olvido, que no ha dejado de hablarse de esos temas, y califica de falsa la historia del "silencio espeso", que un buen número de iniciativas tomadas entonces tuvieron como trasfondo el recuerdo de la República y de la Guerra civil (Cuesta 2007).

Algunos autores afirman que en la Transición pareció producirse un pacto de silencio, en relación con los temas de la guerra civil y la dictadura, y por ello ha sido una transición atravesada por la amnesia social. El olvido voluntario del pasado constituyó parte sustancial del pacto para asegurar el futuro, desaparecieron de la política las referencias al franquismo, y los políticos pasaron a proclamar las virtudes de la democracia, no se pidieron responsabilidades para las viejas, sí, pero largas injusticias. Más aún, se construye una nueva interpretación de la guerra civil, considerándola un choque inevitable, dentro del contexto internacional, del conflicto global entre fascismo, comunismo y capitalismo. En este pacto de silencio, las élites políticas habrían consensuado supuestamente, en los acuerdos políticos, dejar de hacer mención al pasado para así evitar que se repitiera. Tenía como objetivo evitar el riesgo desestabilizador que, para el nuevo régimen democrático, hubiera supuesto todo lo que pudiera alentar la petición de responsabilidades y el ajuste de cuentas por conductas pasadas. Pero el reconocimiento de ese acuerdo tácito, entre los políticos, de no utilizar los recuerdos como arma arrojadiza no quiere decir ni amnesia, ni olvido, ya que en las transiciones pactadas suelen evitarse las políticas retrospectivas para no perturbar las negociaciones.

La investigación histórica en los años 80 mostraba la magnitud de la represión y parte de ese conocimiento historiográfico ha dotado de base empírica a los movimientos que durante años han reivindicado el reconocimiento de las instituciones democráticas a las víctimas del franquismo. Los investigadores e historiadores han aportado un compromiso activo con sus estudios sobre la guerra y la represión para que ya durante la transición no se estableciera el franquismo historiográfico en la democracia. Aparecieron, como consecuencia del descubrimiento de ese pasado oculto, dos nuevos fenómenos: por un lado, una desconocida dimensión social del recuerdo, mal llamado casi siempre memoria histórica, descendientes de esas decenas de miles de asesinados, sus nietos más que sus hijos, se preguntaron qué había pasado, por qué esa historia de muerte y humillación se había ocultado, quiénes habían sido los verdugos y querían, además, saber dónde estaban enterradas las víctimas; a la vez, la generación de los hijos, superado el muro de silencio protector de la etapa franquista, mayoritariamente sentían ese conocimiento como reconocimiento, como un bálsamo reparador del trauma familiar. Las asociaciones de memoria histórica, nacidas a finales del siglo pasado y primeros años del actual, se configurarán en un movimiento social al margen 
de los partidos políticos con una doble dimensión de reivindicación: las reparaciones debidas a las víctimas mediante un programa de aplicación de una justicia transicional y la adopción de políticas públicas de memoria para conformar un relato público basado en valores democráticos y de derechos humanos.

\subsection{Políticas de memoria y justicia transicional en España}

\subsubsection{Políticas de memoria. Reivindicación social de la memoria histórica}

El recién iniciado siglo XXI parece haberse inaugurado bajo un doble signo: el olvido oficial, conmemorativo y memorialístico de la Segunda República y su emergencia popular por los resquicios de las manifestaciones populares anti-gobierno conservador y en los movimientos de protesta y descontento ante los distintos aspectos de la política española.

En España hay un consenso relativo amplio sobre la necesidad de políticas de reparación, que plasman el reconocimiento de las instituciones democráticas hacia quienes lucharon contra la dictadura; estas políticas vienen a reflejar los imperativos éticos de las sociedades libres. No hay, sin embargo, tanto consenso sobre la conveniencia de que los gobiernos desarrollen políticas públicas de la memoria más amplias, las cuales son una necesidad para las sociedades democráticas. En España persiste la ausencia de políticas públicas de memoria reparadoras con respecto a los vencidos de la Guerra Civil y a los luchadores antifascistas frente a las demandas de una sociedad civil agrupada en más de dos centenares de asociaciones, algunas de ellas reconocidas internacionalmente como la Asociación para la Recuperación de la Memoria Histórica, que junto con el Foro por la Memoria son las más conocidas en España al establecer una red de asociaciones federadas en diferentes provincias. La transición y su sombra del recuerdo de la guerra civil mediante unas reglas mordaza deja aparcados temas o cuestiones divisorios o polémicos, presidiendo importantes decisiones políticas como la ausencia de medidas de justicia política y de debate sobre ellas, por el deseo obsesivo de evitar la repetición del enfrentamiento fratricida.

En la actualidad la reivindicación social en torno a la necesidad de políticas de memoria democrática continúa siendo igualmente necesaria pues sectores significativos de la sociedad española continúan manifestando actitudes de rechazo hacia la asunción por parte de las instituciones democráticas de la significación del franquismo y sus prácticas represivas sobre una parte muy amplia de esa misma sociedad.

La producción historiográfica es ingente; no obstante, todos sabemos que la mayoría no conoce sus conclusiones, a veces ni incluso su existencia; aunque las investigaciones se publican y por tanto teóricamente son accesibles a todo el mundo, en realidad la socialización del conocimiento histórico se realiza en buena medida a través de la memoria pública -la extendida por los canales públicos y privados; es por eso que son imprescindibles políticas públicas de la memoria que, fundamentadas en el conocimiento histórico, contribuyan a fortalecer los valores democráticos. La lucha por desenterrar ese pasado, el conocimiento de la verdad y el reconocimiento jurídico y político de esas víctimas nunca fueron señas de identidad de nuestra transición a la democracia, y un sector importante de la sociedad muestra todavía una notable indiferencia hacia la causa de quienes padecieron tanta persecución. Los mitos y ecos de la propaganda franquista se imponen a la información veraz porque cientos de miles de personas poco o nada aprendieron en las aulas sobre esa historia y porque algunos medios de comunicación jalean y aplauden a los pseudohistoriadores (Casanova, 2010)

Con la expresión "memoria de los vencidos" determinados sectores reivindican un relato del pasado que lo explique a la luz de los valores democráticos y de reivindicación de aquéllos que se opusieron a la dictadura. La dictadura dejó una pesada herencia en el 
imaginario colectivo y ahora es deber de las instituciones democráticas impulsar políticas activas que faciliten la incorporación del conocimiento riguroso del pasado a la memoria pública la historia informe la memoria (Molinero, 2007). La memoria histórica de la Guerra Civil y el Franquismo es un ejemplo de memoria traumática, de percepción de derrota colectiva que no ha sido asumida en la sociedad española como un valor moral en el presente, como una vía de aprendizaje político, ideológico y cultural, de este modo los usos públicos de la historia y las políticas de memoria no han satisfecho las demandas de los vencidos en la Guerra Civil. Las víctimas han sufrido una doble ofensa, la agresión física de sus verdugos y la tortura psicológica de ser llevados en su memoria (Ruiz Vargas, 2004). Al contrario de lo que ha pasado en Europa con sus guerras, en España, los valores de los perdedores de la guerra han sido excluidos del imaginario colectivo y de la representación social del pasado.

Uno de los legados de la dictadura franquista es la inexistencia de una memoria antifascista institucionalizada para explicar nuestro pasado común, nos hemos acostumbrado a convivir con esta deficiencia, es un déficit democrático consecuencia del pacto de silencio en aras de la reconciliación nacional, dejando sin voz u olvidados a los testimonios de la lucha antifranquista y no teniendo ninguna sensibilidad por la conservación de los lugares de memoria. (Gálvez Biescas, 2008) La resolución de este conflicto no tendrá más consecuencias políticas que las de superar uno de los "déficit democráticos" de nuestra sociedad. A pesar de que ese pasado está aún muy presente, escasas son las posibilidades reales de que la Justicia pudiera intervenir para exigir responsabilidades a los ejecutores de la Dictadura. En este asunto, y a diferencia de lo sucedido en países como Alemania o recientemente en Chile o Argentina, no ha surgido, ni se ha planteado, la exigencia de responsabilidades a los dirigentes de la dictadura franquista salvo las iniciativas internacionales como la emprendida por la Justicia argentina. En la sociedad española actual se evidencia la existencia de una pluralidad de memorias "relegadas" en el hilo de la historia, pero con elementos compartidos; la crítica creciente del discurso histórico -o paradigmadominante; y la entrada en escena de los Derechos Humanos como base jurídica y ética para la reconstrucción de un pasado sometido a una intensa revisión (Gálvez Biescas, 2008).

Mientras hablar de nuestro pasado reciente y de sus protagonistas marginados -las víctimas del franquismo- se encuentre sujeto a intereses o luchas interpartidistas y mediáticas, o a estrictos cálculos políticos, ni las víctimas del franquismo recibirán el trato que les es propio, ni los historiadores y científicos sociales podrán actuar con entera libertad ni normalidad en su quehacer. Aunque lentamente se van superando las anomalías que han acompañado a buena parte de la historiografía contemporánea española. La propia inclusión de «crímenes contra la humanidad» para referirse a nuestros episodios traumáticos nos hablan de ello (Gálvez Biescas, 2008). El otro gran paso en esta línea, y en el que sin duda la voluntad política y las actuaciones por parte de la Administración del Estado -y también por parte de las Comunidades Autónomas- tendrán una notable influencia, será reconducir el debate acerca de la Guerra Civil, y en concreto de la represión franquista, por los canales que le son propios.

En el debate actual sobre las políticas públicas que se podrían aplicar para la recuperación de la memoria histórica relacionada con la guerra civil y la represión franquista en España, extraña la ausencia casi total de referencias al Derecho internacional contemporáneo y a la práctica y a los mecanismos internacionales y estatales aplicados en experiencias parecidas recientes y no tan recientes que permiten situar claramente este debate como una cuestión no sólo histórica sino de justicia y de derechos humanos. En la actualidad, desde la perspectiva 
de una sociedad democrática no se entiende una visión exclusivamente histórica de la situación anómala en que todavía viven en España las víctimas y familiares de víctimas de crímenes de guerra, crímenes contra la humanidad y de violaciones muy graves de derechos humanos perpetradas durante la guerra y la posterior represión contra el bando "republicano": ni en comparación con las víctimas del bando "nacional", reconocidas y reparadas anchamente por el régimen franquista, ni tampoco en comparación con las víctimas de los crímenes nazis en Alemania y a los territorios ocupados por el Eje, coetáneos a los crímenes cometidos en España pero condenados y perseguidos de forma incontestada todavía más de cincuenta años después de su comisión. La carencia de una reparación efectiva a estas víctimas directas y la inexistencia de mecanismos administrativos y judiciales al alcance de los familiares que exigen conocer la verdad de su propio pasado (por las dificultades de acceso a los archivos y a los registros civiles o por el vacío legal en materia de localización y exhumación de fosas comunes, por ejemplo) se han traducido en una sensación de injusticia y de vulneración de derechos fundamentales que, a nuestro parecer, ha sido la semilla del movimiento para la recuperación de la memoria histórica en España, formado en gran parte por nietos de las víctimas de la represión franquista, que reivindican justicia, entendida no como venganza sino como el elemento necesario para poder hablar de reconciliación y de paz.

\subsubsection{Políticas de memoria para después de una guerra. Franquismo y transición}

La única política de memoria realizada en España ha sido la del franquismo con su Causa General, que por vía judicial se exhumó y dignificó a sus víctimas provincia a provincia, pueblo a pueblo, y se castigó a los culpables, todo ello con cargo a los presupuestos del Estado; los vencedores fueron amnistiados de todos los hechos cometidos durante la guerra, gozaron de homenajes, se beneficiaron de incautaciones y del acceso a puestos del funcionariado entre otras prebendas (Espinosa, 2013).

En los últimos 30 años, desde el comienzo de la transición, se adoptaron y aprobaron diversas medidas reparadoras hacia las víctimas de la guerra civil y el franquismo: la Ley de Amnistía en 1977, normativa sobre pensiones a militares republicanos, amnistía a funcionarios de la Generalitat de Catalunya y de Justicia en 1978 y sobre pensiones de viudas de guerra en 1979, sobre contribuciones a la Seguridad Social por años de estancia en prisión y sobre pensiones a militares no profesionales incorporados a partir del inicio de la guerra en 1984, sobre la rehabilitación de militares de la UMD en 1986. Eran una serie de medidas que pretendían equiparar en derechos pero no reconocer la justicia de la causa de los vencidos. En 1988 se aprueba la Ley de Devolución del Patrimonio Sindical, en 1990 indemnizaciones por años de estancia en prisión, en 1996 se dota de nacionalidad española a los miembros de las Brigadas Internacionales y en 1998 se aprueba la devolución del patrimonio perdido tras la guerra a los partidos políticos. En el año 2005 se aprueban medidas relativas a los niños de la guerra y subvenciones a asociaciones de memoria histórica, en 2006 se aprueba la restitución de documentos de la Generalitat Catalunya depositados en el Archivo de la Guerra Civil de Salamanca y finalmente en 2007 se aprueba la Ley de la Memoria.

Temas polémicos como la existencia de fosas comunes, la carencia de información sobre los desaparecidos, la negativa gubernamental y judicial a anular sentencias franquistas o la existencia todavía de simbología franquista revelan la necesidad de afrontar una situación claramente anómala en una sociedad democrática y comprometida con los derechos humanos, de acuerdo precisamente con una perspectiva de derechos humanos y con políticas públicas que incorporen la experiencia de otros Estados y los principios internacionales aplicables al caso español. Sólo así habrá paz y justicia y se podrá hablar de reconciliación. 


\subsubsection{La Ley de la Memoria Histórica}

La Ley 52/2007, de 26 de diciembre, por la que se reconocen y amplían derechos y se establecen medidas en favor de quienes padecieron persecución o violencia durante la guerra civil y la dictadura -conocida como Ley de la Memoria Histórica-, explica, en su exposición de motivos, que el espíritu de la Transición da sentido al modelo constitucional de convivencia más fecundo que hayamos disfrutado nunca y enumera y describe las diversas medidas y derechos que se han ido reconociendo, desde el origen mismo de todo el período democrático, en favor de las personas que, durante los decenios anteriores a la Constitución, sufrieron las consecuencias de la guerra civil y del régimen dictatorial que la sucedió.

Es pues una continuidad en las medidas ya adoptadas, reconociendo que quedan peticiones legítimas y justas que el Estado no puede dejar de atender. La Ley asume esta Declaración así como la condena del franquismo contenida en el Informe de la Asamblea Parlamentaria del Consejo de Europa firmado en París el 17 de marzo de 2006 en el que se denunciaron las graves violaciones de Derechos Humanos cometidas en España entre los años 1939 y 1975. Aboga por honrar y recuperar para siempre a todos los que directamente padecieron las injusticias y agravios producidos, por unos $\mathrm{u}$ otros motivos políticos o ideológicos o de creencias religiosas durante la guerra y el franquismo desde el espíritu de reconciliación y concordia, y de respeto al pluralismo y a la defensa pacífica de todas las ideas, que guio la Transición y se recogieron en la Constitución de 1978. La ley sienta las bases para que los poderes públicos lleven a cabo políticas públicas dirigidas al conocimiento de nuestra historia y al fomento de la memoria democrática circunscribiendo su actuación como dice en su artículo 1 al "fomento de los valores y principios democráticos".

La Ley 52/2007 de la Memoria Histórica propone algunos elementos de ruptura pero no cumple con la legalidad internacional ni facilita el acceso de las víctimas a la justicia, proclama la ilegitimidad e injusticia de las sentencias judiciales del franquismo pero no su nulidad, privatiza la búsqueda y localización de desaparecidos delegando en entidades sociales esta tarea tal como aparece a los artículos del 11 al 14, de este modo está desatendiendo el derecho internacional a pesar de la ratificación por parte del Estado español durante aquel tiempo de la Convención Internacional por la protección de todas las personas contra las desapariciones forzadas de 27 de octubre de 2008 (Sáez, 2013).

Con la llegada al poder del Partido Popular se paraliza prácticamente el desarrollo de la ley y de normativa relacionada, suprimiéndose la Oficina de Víctimas y las subvenciones para actuaciones relacionadas con la memoria histórica.

\subsubsection{Políticas acerca del derecho a la verdad. Archivos}

La Ley 30/1992, de 26 de noviembre, de Régimen Jurídico de las Administraciones Públicas y del Procedimiento Administrativo Común, reconoce en su artículo 35.h) el derecho de los ciudadanos al acceso los registros y archivos de las Administraciones Públicas en los términos previstos en la Constitución y en ésta u otras leyes; y en el artículo 37.g) remite el acceso a los Archivos Históricos a su regulación específica. Esta regulación específica se encuentra en la Ley 16/1985, de 25 de junio, del Patrimonio Histórico Español. La Comisión Interministerial para el estudio de la situación de las víctimas de la Guerra Civil y del franquismo, realizó un informe sobre los archivos y determinó que una sociedad democrática y con conciencia de su identidad cultural tiene la obligación de conservar estos fondos y organizarlos de manera que resulten realmente accesibles para los investigadores y para el conjunto de los posibles interesados. En términos generales, estos fondos están localizados, pero queda aún mucho por hacer en términos de catalogación y concentración, 
porque se hallan dispersos, mal catalogados y en general no digitalizados; en conjunto, no puede decirse que esta documentación este bien controlada, en muchos casos los documentos se hallan sometidos a precarias condiciones de conservación. Las posibilidades reales de una investigación dependen, muchas veces, de factores como el desconocimiento de la existencia de los fondos, su embrionario estado de catalogación, la ausencia de digitalización o, en ocasiones, las peculiaridades de los organismos públicos o entidades privadas que los custodian, y de unas normas de acceso homogéneas. Es necesario un plan general de actuación y que se inicien los trabajos para una necesaria ley de Archivos y Documentos. España es el único país de la Unión Europea que carece de una ley de Archivos. No se ha garantizado aún el derecho a la verdad.

Una de las prioridades de la Ley de Memoria Histórica es la recopilación y difusión de la información histórica y de los documentos relativos a la Guerra Civil, al exilio y a la dictadura, según dispone en sus artículos 20 a 22. En este contexto se crea el Centro Documental de la Memoria Histórica ubicado en Salamanca, el cual integra el Archivo General de la Guerra Civil y pretende integrar todos los documentos referentes a la Guerra Civil y la represión política. Los procedimientos sumarísimos -consejos de guerra y otrosinstruidos durante la guerra civil y la dictadura se conservan principalmente en los archivos judiciales militares. El Ministerio de Defensa ha realizado un esfuerzo para orientar al interesado en la localización de los procedimientos; asimismo, se han puesto en marcha en los últimos años diversas iniciativas, para la catalogación informática y la digitalización de los fondos judiciales militares.

Una serie de medidas posteriores trabajan en la dirección de facilitar el acceso a archivos y fondos documentales, y el derecho a la verdad de los ciudadanos como la elaboración de bases de datos sobre víctimas del franquismo, de militares del Ejército de la República desaparecidos o deportados a campos de concentración nazis; también se ha publicado reciente normativa que facilita al investigador el acceso a documentación judicial hasta hace poco de difícil consulta como es el caso de los libros de defunción de los Registros Civiles.

\subsubsection{El derecho a la Justicia en España}

El artículo 2 de la Ley de la Memoria Histórica hace una proclamación general del carácter injusto de todas las condenas, sanciones y expresiones de violencia personal producidas, por motivos inequívocamente políticos o ideológicos, durante la Guerra Civil, así como las que, por las mismas razones, tuvieron lugar en la Dictadura posterior. En el artículo 3 se declara la ilegitimidad de los tribunales, jurados u órganos de cualquier naturaleza administrativa creados con vulneración de las más elementales garantías del derecho a un proceso justo, así como la ilegitimidad de las sanciones y condenas de carácter personal impuestas por motivos políticos, ideológicos o de creencias religiosas; una disposición derogatoria priva de vigencia jurídica a aquellas normas dictadas bajo la Dictadura manifiestamente represoras y contrarias a los derechos fundamentales.

El Estado se inhibe en las tareas de búsqueda y localización de desaparecidos, recogiéndose diversos preceptos (arts. 11 a 14) que, atendiendo una muy legítima demanda de no pocos ciudadanos, que ignoran el paradero de sus familiares, algunos aún en fosas comunes, prevén medidas e instrumentos para que las Administraciones públicas faciliten, a los interesados que lo soliciten, las tareas de localización, y, en su caso, identificación de los desaparecidos. La Ley de la Memoria establece una mera colaboración de la Administración General del Estado elaborando planes de trabajo y estableciendo subvenciones para sufragar gastos derivados de las actividades contempladas; elaborando un protocolo de actuación científica y multidisciplinar que asegure la colaboración institucional y una adecuada 
intervención en las exhumaciones, confeccionándose un mapa integrado de fosas que comprenda todo el territorio español.

En España el Estado no ha creado un entramado judicial para la denuncia, la investigación y el enjuiciamiento de casos de violaciones de derechos en relación a la Guerra Civil y el Franquismo; al contrario la Ley de Amnistía de 1977 como todas las leyes de este tipo son contrarias al derecho internacional por ser violaciones del derecho a la justicia internacionalmente reconocido. No se ha hecho justicia pues no se ha investigado de manera imparcial ni se han perseguido ninguno de los crímenes cometidos por uno de los contendientes en la Guerra Civil; ni ha habido ninguna iniciativa tendente a crear un Plan de Derechos Humanos que examine pormenorizadamente las violaciones de éstos de las víctimas y familiares, el único intento habido en este sentido, el auto del juez Baltasar Garzón de la Audiencia Nacional de octubre de 2008 declarándose competente para investigar las denuncias presentadas por las Asociaciones de la Memoria Histórica sobre los crímenes y desapariciones del franquismo y ordenando que se inicien las exhumaciones de los cadáveres de 19 fosas comunes, que posteriormente se inhibió a favor de 62 juzgados territoriales para que continuará la investigación, y terminó con la denuncia por prevaricación contra el juez, su procesamiento y la declaración de incompetencia por parte del Tribunal Supremo para investigar estas causas. Actualmente solo la vía internacional es la que permanece abierta para reclamar responsabilidades e investigar los crímenes del franquismo con iniciativas llevadas a cabo por la justicia Argentina o las diferentes recomendaciones realizadas por organismos dependientes de la ONU.

\subsubsection{Reparación.}

El artículo 4 de la Ley de Memoria Histórica reconoce el derecho a la reparación moral y al reconocimiento personal a quienes durante la Guerra Civil y la Dictadura franquista perdieron la vida o su libertad, sufrieron internamiento en campos de concentración o trabajos forzados, fueron empujados a un irreversible exilio, padecieron persecuciones, condenas, sanciones o cualesquiera otras formas de violencia personal por razones políticas, ideológicas o de creencia religiosa, sin suponer el reconocimiento de responsabilidad patrimonial del Estado ni de cualquier Administración Pública.

La Ley de Memoria Histórica también incluye la mejora de las indemnizaciones económicas y de las pensiones a las víctimas de la Guerra Civil y el franquismo. Hasta 2007 existían varias compensaciones que, tras la entrada en vigor de la norma, se han ampliado a familiares de fallecidos en la Guerra Civil, así como los fallecidos por sus actuaciones u opiniones políticas y sindicales, entre otros, a aquellos que sufrieron prisión como consecuencia de los supuestos contemplados en la Ley de Amnistía. Por otra parte, ya antes de la aprobación de la Ley, se instituyeron también ayudas a los conocidos como "Niños de la Guerra", españoles menores de edad que fueron desplazados a otros países, en especial a Rusia, como consecuencia de la Guerra Civil. Se prevé el derecho a una indemnización en favor de todas aquellas personas que perdieron la vida en defensa de la democracia y de las libertades entre el 1 de enero de 1968 y el 6 de octubre de 1977, de la democracia que hoy todos disfrutamos, y que no habían recibido hasta ahora la compensación debida (art. 10). No se ha realizado ninguna depuración del funcionariado, ni se ha ilegalizado al partido que hasta los últimos días de la Dictadura franquista participó activamente en la represión política.

Las políticas de reparación, en relación a la puesta en valor de los lugares de memoria en muchas ocasiones, han sido impulsadas por organizaciones y asociaciones, y por diferentes 
administraciones locales y autonómicas, pero se adolece de una política de memoria decidida por parte de la Administración del Estado en este sentido. La memoria necesita expresarse por unos soportes externos como los testimonios orales, el patrimonio, creando así recordatorios informativos como los lugares de memoria después de tantos años de olvida los hechos y destruir patrimonio, los lugares de historia de la represión han de convertirse en lugares de memoria. Las medidas y políticas respecto a la retirada de simbología franquista también son consideradas una importante política activa reparatoria hacia las víctimas. La Ley de la Memoria Histórica establece en sus artículos 15 y 16 actuaciones al respecto sobre la retirada de los símbolos y monumentos conmemorativos de la Guerra Civil o de la Dictadura, sustentadas en el principio de evitar toda exaltación de la sublevación militar, de la Guerra Civil y de la represión de la Dictadura, entre estas medidas podrá incluirse la retirada de subvenciones o ayudas públicas si se produce su incumplimiento. Pero también se establece que estas medidas no serán de aplicación cuando las menciones sean de estricto recuerdo privado, sin exaltación de los enfrentados, o cuando concurran razones artísticas, arquitectónicas o artístico-religiosas protegidas por la ley.

\subsubsection{Políticas de memoria en las comunidades autónomas}

Algunas comunidades autónomas han desarrollado durante los últimos años políticas más o menos activas relacionadas con la memoria histórica, incluso creando organismos o departamentos al efecto; generalmente han sido las no gobernadas por el Partido Popular, y cuando unas elecciones autonómicas ha cambiado el signo político del gobierno las políticas de la memoria se han congelado o eliminado.

Excepto algunas acciones llevadas a cabo en Andalucía o Catalunya la mayor parte de políticas de memoria han tenido relación con las medidas reparatorias respecto a las víctimas de la guerra y el franquismo, y actividades de difusión mediante jornadas, homenajes, conferencias, investigaciones y proyectos relacionados con aquella etapa histórica; sin apenas desarrollarse iniciativas y acciones sobre el esclarecimiento e investigación judicial e histórica de los hechos acaecidos. Cataluña fue la primera comunidad autónoma en incluir en su Estatuto de Autonomía una ley específica referida a la memoria histórica, pero son las comunidades autónomas de Andalucía y el País Vasco las que recogen taxativamente en sus políticas de memoria -con la tramitación de la ley andaluza y la creación del Programa de Memoria Histórica del Gobierno Vasco- intenciones de seguir las recomendaciones de la ONU a España en cuestión de derechos humanos sobre las víctimas del franquismo y en seguir y recoger en sus disposiciones los principios del Derecho Internacional de Verdad, Justicia y Reparación.

\subsection{Experiencias internacionales sobre políticas de memoria}

Las políticas de memoria y de justicia transicional desarrolladas en España pueden compararse con las de otros países que han vivido dictaduras que han supuesto etapas traumáticas en cuanto a violaciones de derechos humanos. Podemos advertir como en Chile y Argentina al ser más reciente la experiencia traumática de la represión, la sociedad nunca dejó de movilizarse contra la impunidad.

Las amnistías son medidas a las que se recurre en los estados que viven transiciones buscando la estabilidad y la viabilidad del nuevo régimen democrático. En Argentina se pudo lograr el procesamiento de las cúpulas militares a finales de 1983 tras derogarse la ley de pacificación nacional impulsada por los militares en abril de 1983, las asonadas militares provocaron la ley de punto final y de obediencia debida de 1986 y 1987, y el gobierno de Carlos Menem decretó indultos en 1989 y 1990; los casos de apropiación de menores y 
desaparición de embarazadas no se vieron afectados por las leyes aprobadas y la justicia siguió su curso; en 1996 y 2000 se celebraron juicios de la verdad y se estableció una comisión de la verdad para resarcir a las víctimas y conocer la verdad de lo ocurrido. En 2001 la justicia argentina decreta la inconstitucionalidad de las leyes de punto final y obediencia debida y se reabren los megajuicios a militares implicados en la represión anulándose los indultos del gobierno de Menem.

En Chile la ley de amnistía aprobada en 1978 por los militares no ha sido derogada pero la detención de Pinochet y el reconocimiento por la justicia de algunos delitos como imprescriptibles hacen que algunos jueces abran procesos contra los represores, investigando los jueces los casos antes de aplicar la ley mientras que en España se archivan sin realizar investigación. En Chile la Justicia decidió que el Derecho Internacional tenía preeminencia sobre ley de amnistía. El Estado debería poner sus grandes recursos materiales y humanos al servicio de la investigación y esto en España no se ha hecho. Sería de gran utilidad la creación en España de Comisiones de la Verdad para hacer accesible la información en un corto periodo de tiempo, que los historiadores elaboren un relato coherente y fidedigno de lo que pasó, tienen utilidad simbólica y moral pues dan voz a las víctimas, se publicitan a gran escala los episodios de violaciones de derechos humanos, documenta la forma de operar de las dictaduras y están dotadas de prestigio y credibilidad por los miembros que las conforman.

Argentina y Chile pusieron en funcionamiento comisiones de la verdad, informes públicos, algo que no se ha impulsado en España donde ahora empiezan a tomar fuerza las iniciativas de las asociaciones memorialistas sobre investigación y localización de las víctimas. La Comisión Constitucional en España reconoce a las víctimas de la guerra y el franquismo pero el Estado no les pide perdón como se hace en Chile y Argentina, lugares donde organismos del Estado se encargan de localizar e investigar las fosas y las exhumaciones judicial y científicamente, mientras que en España la localización de fosas y desaparecidos se ha dejado en manos de asociaciones de memoria mediante subvenciones. Las medidas de reparación han llegado mucho más lejos en estos dos países latinoamericanos, con profusión de lugares de memoria, museos de víctimas, cementerios, antiguos centros de detención y represión reconvertidos en espacios de memoria; por el contrario en España no hay ningún monumento nacional que recuerde a las víctimas del franquismo ni las recuerda ninguna fecha conmemorativa. En relación a las reparaciones materiales, se redactaron cuatro textos al respecto en Argentina, en Chile entró en vigor un salario mensual para las familias de los desaparecidos con ventajas sociales y se aprobaron ayudas económicas para facilitar el retorno de los exiliados; en España no se ha llevado a cabo la devolución del patrimonio incautado tras la guerra a los particulares, lo que sí se ha hecho vía judicial en Argentina.

\section{BIBLIOGRAFÍA}

AGUILAR FERNÁNDEZ, P. (2008). Políticas de la memoria y memorias de la política. Madrid: Alianza.

AGUILAR FERNÁNDEZ, P. (2002). "Justicia, política y memoria: los legados del franquismo en la transición española", en A. Barahona de Britto Las políticas hacia el pasado Juicios, depuraciones, perdón y olvido en las nuevas democracias. Madrid: Istmo, pp. 135-194. 
BARAHONA DE BRITTO, A. (ed.) (2002). Las políticas hacia el pasado Juicios, depuraciones, perdón y olvido en las nuevas democracias. Madrid: Istmo.

CAPELLA ROIG, M. (2007). "Aportacions de la Justícia Transiccional a les polítiques públiques de memòria”, en Jornada de Memoria Històrica. Barcelona: Institut de Drets Humans de Catalunya.

CARRILLO CASTELLÓ, M. (2006). "El marco legal de la represión en la dictadura franquista durante el periodo 1939-1959”, en F. Gómez Isa (dir.) El derecho a la memoria. San Sebastián: Departamento para los Derechos Humanos, el Empleo i la Inserción social de la Diputación Foral de Gipuzkoa, pp. 501-528.

CASANOVA RUIZ, J. (2010). "Sinfonía de maldad” en El País http://elpais.com/diario/2010/ 05/23/opinion/ 1274565605_850215.html [consulta 9/5/2015].

CHINCHÓN ÁLVAREZ, J. (2010). "La investigación de los crímenes cometidos en la guerra civil y el franquismo como delito de prevaricación. Análisis crítico del auto del Tribunal Supremo de 3-2-2010 desde la perspectiva del derecho internacional". Revista Electrónica de Estudios Internacionales, pp. 143.

CHINCHÓN ÁLVAREZ, J. (2009): “Justicia Transicional, 'Memoria Histórica' y responsabilidad internacional del Estado: Un análisis general a propósito del cumplimiento de ciertas obligaciones internacionales en juego después de más de tres décadas del inicio formal de la transición política española". Revista de Derecho de Extremadura, pp. 49-74.

CUESTA BUSTILLO, J. (2007). "Las capas de la memoria. Contemporaneidad, sucesión y transmisión generacionales en España (1931-2006)" en Hispania Nova, Revista de historia contemporánea, $\mathrm{n}^{\circ} 7$ Separata.

CUESTA BUSTILLO, J. (2007). "Recuerdo, silencio y amnistía en la Transición y en la Democracia españolas (1975-2006)" en Studia Historica. Historia contemporánea, 25: 125-165.

CUESTA BUSTILLO, J. (1998). "Memoria e historia. Un estado de la cuestión" en Ayer, Memoria e historia, pp. 203-246.

ESCUDERO ALDAY, R. (2013). "Los desaparecidos en España: víctimas de la represión franquista, símbolo de la transición y síntoma de una democracia imperfecta", en R. Escudero Alday (ed.) Desapariciones forzadas, represión política y crímenes del franquismo. Madrid: Trotta, pp. 141-161.

ESCUDERO ALDAY, R. (ed.) (2013). Desapariciones forzadas, represión política y crímenes del franquismo. Madrid: Trotta.

ESPINOSA MAESTRE, F. (2013). "Crímenes que no prescriben. España (1936-1953)", en R. Escudero Alday (ed.) Desapariciones forzadas, represión política y crímenes del franquismo. Madrid: Trotta, pp. 31-53.

GABORIT, M. (2006). "Memoria histórica: revertir la historia desde las víctimas". ECA, Estudios centroamericanos, pp. 663-684.

GÁLVEZ BIESCAS, S. (2008). "Memorias, historia, derechos humanos, políticas públicas: reflexiones en torno a la práctica historiográfica. Conclusiones", en Hispania Nova, 8: 1-16.

GÁLVEZ BIESCAS, S. (2006). "El proceso de la recuperación de la memoria histórica en España: una aproximación a los movimientos sociales por la memoria", en International Journal of Iberian Studies, 19 (1): 25-51.

GARCÍA ÁLVAREZ, J. (2009). "Lugares, paisajes y políticas de memoria: una lectura geográfica" en Boletín de la AGE, pp. 175-202.

GÓMEZ ISA, F. (2007): "Reparación, memoria y derecho a la paz", en C.R. Rueda Castañón y C. Villan Durán (eds.) La Declaración de Luarca sobre el derecho humano a la paz. Siero: Ediciones Madú, pp. 479-490.

GÓMEZ ISA, F. (2006). "El derecho de las víctimas a la reparación por violaciones graves y sistemáticas de los derechos humanos", en F. Gómez Isa (dir.) El derecho a la memoria. San Sebastián: Departamento para los Derechos Humanos, el Empleo i la Inserción Social de la Diputación Foral de Gipuzkoa, pp. 25-75.

LÓPEZ CENDÓN, C. (2007). "La 'Ley de reparación a víctimas de la Guerra Civil y del Franquismo', un pésimo precedente contra la impunidad" en Amnistía, 85: 37-42.

MENDEZ, J. E. (2013). "Justicia de transición", en R. Escudero Alday (ed.) Desapariciones forzadas, represión política y crímenes del franquismo. Madrid: Trotta, pp. 13-30. 
MOLINERO RUIZ, C. (2007). "Represión franquista y políticas públicas de memoria" en Conference on Historical Memory: Policy and Practice, Catalan Oberservatory, London School of Economics and Political Science.

PÉREZ GARZÓN, J. S. (2008). "Una història crítica per a una memòria sense exclusions", en S. Gálvez Biescas (dir.) Preses de Franco. Barcelona: Fundación de Investigaciones Franquistas, pp. 31-33.

PÉREZ GONZÁLEZ, C. (2013). "Derecho a la verdad y desapariciones forzadas durante la guerra civil y el franquismo: una perspectiva desde el derecho internacional", en R. Escudero Alday (ed.) Desapariciones forzadas, represión política y crímenes del franquismo. Madrid: Trotta, pp. 55-74.

REYES MATE, M. (2009). La significación política de las víctimas. Buenos Aires: Nuestra Memoria. Museo de la Memoria Shoah Buenos Aires.

RODRIGO SÁNCHEZ, J. (2006). "Ecos de una guerra presente. 'Memoria', 'olvido', recuperación e instrumentación de la Guerra Civil Española", en M. D. De la Calle Velasco (ed.): Guerra civil: documentos y memoria. Salamanca: Universidad de Salamanca, pp. 145-170.

RODRÍGUEZ ARIAS, M. A. (2010): Ley de verdad, justicia y reparación para las víctimas del genocidio y la dictadura franquista y el posterior periodo de impunidad. Anteproyecto de Iniciativa Legislativa Popular formulada al amparo de la Ley Orgánica 3/1984, de 26 de marzo.

RUIZ VARGAS, J. M. (2004). "Los gritos de la memoria", en http://www.foroporlamemoria.info/docu mentos/2004 [consulta 15/5/2015].

SÁEZ VALCÁRCEL, R. (2013): "Los crímenes de la dictadura y la negación de acceso a la jurisdicción", en R. Escudero Alday (ed.) Desapariciones forzadas, represión política y crímenes del franquismo. Madrid: Trotta, pp. 77-99.

SCHABAS, W. A. (2006). "Comisiones de la Verdad y Memoria", en F. Gómez Isa (dir.) El derecho a la memoria. San Sebastián: Departamento para los Derechos Humanos, el Empleo y la Inserción Social de la Diputación Foral de Gipuzkoa, pp. 101-112.

\section{Breve currículo:}

\section{Juan Luis Porcar Orihuela}

Juan Luis Porcar Orihuela, archivero-técnico documentalista de la Universidad Jaume I. Licenciado en Geografía e Historia por la Universidad de Valencia. Ha publicado diversas obras sobre la guerra civil, el franquismo y la memoria histórica, diferentes artículos en revistas especializadas, y ha participado en diferentes cursos, congresos, jornadas y conferencias. Destacan las obras: Castelló sota les bombes; La memòria i les víctimes; La cultura exiliada; Un país en gris i negre: memòria històrica i repressió franquista a Castelló; El temps perdut: memòria històrica de Vistabella. 